\title{
Treatment outcomes of Acute Appendicitis and associated factors among admitted patients with a diagnosis of Acute Abdomen in Debre Markos referral hospital, Amhara region, North West Ethiopia
}

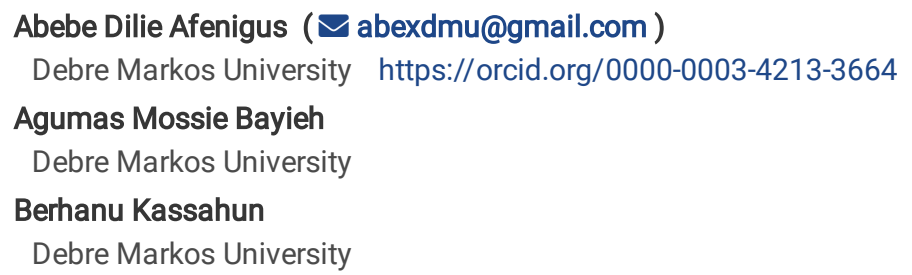

Research article

Keywords:

Posted Date: June 21st, 2019

DOI: https://doi.org/10.21203/rs.2.10530/v1

License: @) (i) This work is licensed under a Creative Commons Attribution 4.0 International License. Read Full License

Version of Record: A version of this preprint was published at Journal of Perioperative Practice on July 8th, 2020. See the published version at https://doi.org/10.1177/1750458920928473. 


\section{Abstract}

Introduction- Acute abdomen is a sudden onset abdominal disease condition which often requires an immediate surgical intervention. Appendicitis is an inflammation of the vermiform appendix and is one of the most common causes of an acute abdomen in young adults. Appendicitis can cause severe periumbilical pain that radiates to the right lower quadrant, nausea, vomiting and anorexia. If left untreated, it can also cause appendiceal abscess, perforation and peritonitis. Objective - To assess treatment outcomes of Acute Appendicitis and associated factors among admitted patients with a diagnosis of acute abdomen in Debre Markos referral hospital from September 11/2018 to March 9/2019. Methods and materials - Institutional based cross sectional study was employed among 169 patients using a census sampling method. Data were collected from patient medical records, registration books and anesthesia charts available in the hospital by using checklist. Data was entered using Epidata version 4.2 and analyzed by SPSS version 25 software. Logistic regression analysis was employed to describe the relationship between outcome and predictor variables. Results - Among 303 patients with a diagnosis acute abdomen, 169(55.7\%) were developed acute appendicitis, of whom, 107(63.7\%) were males and $62(36.7 \%)$ were females. Among 169 patients who underwent appendectomy for treatment of acute appendicitis, $45(26.6 \%)$ of them were developed unfavorable treatment outcomes. The odds of unfavorable treatment outcomes for acute appendicitis was higher among patients who had elevated WBC count at the time of presentation $[A O R=4.7 ; 95 \% \mathrm{Cl}(1.95,11.35)]$ as compared with their counterparts. Similarly, those patients who had an intraoperative appendiceal abscess were more likely to have unfavorable treatment outcome for acute appendicitis [AOR=3.8; $95 \% \mathrm{Cl}(1.61,9.07)]$ as compared to those who didn't have appendiceal abscess. Conclusion and recommendation- Nearly one-fourth of patients who underwent appendectomy for appendicitis treatment were developed unfavorable treatment outcomes. Elevated WBC count at the time of presentation and presence of intraoperative appendiceal abscess were the factors associated with unfavorable treatment outcome of acute appendicitis. Therefore, immediately evaluate patients having similar features with laboratory investigations is crucial.

\section{Introduction}

Acute abdomen is a condition of sudden severe abdominal pain, usually requiring emergency surgery, caused by acute diseases of or injury to internal organs. The commonest symptoms in patients with acute abdomen were abdominal pain, vomiting, abdominal distension and constipation. Acute appendicitis is one of the major causes of acute abdomen. The other causes of acute abdomen include cholelithiasis, intestinal obstruction, peptic ulcer perforation, acute pancreatitis and obstetric and gynecological related diseases (1-4).

The appendix is an immunologic organ that participates in the secretion of immunoglobulin, such as immunoglobulin A. Appendicitis is defined as inflammation of the vermiform (worm-shaped) appendix, a narrow blind ending pouch approximately 5 - $9 \mathrm{~cm}$ long opening off the caecum. Acute appendicitis is the most common cause of an acute abdomen in young adults. Appendicitis is thought to result from obstruction of the appendiceal lumen, typically by lymphoid hyperplasia, but occasionally by a fecalith, foreign body, or even worms. Obstruction of the lumen by fecalith or lymphoid tissue results in distention of the appendix, bacterial overgrowth, and infection, venous and lymphatic congestion, ulceration and transmural spread of infection through the appendicular wall. The inflammation and infection may result in thrombosis of blood vessels causing ischemia, necrosis and perforation. If untreated, necrosis, gangrene, and perforation occur. If the perforation is contained by the omentum, an appendiceal abscess results (5-7).

Appendectomy, which is the gold standard in the management of acute appendicitis, is the most frequently performed urgent abdominal operation and is often the first major procedure performed by a surgeon in training. Advances in modern radiographic imaging have improved diagnostic accuracy; however the diagnosis of appendicitis remains essentially clinical, requiring a mixture of observation, clinical acumen and surgical science and as such it remains an enigmatic challenge and a reminder of the art of surgical diagnosis $(5,8)$.

Appendicitis can occur at any age but is most common in adolescents and young adults. It causes vague abdominal pain that starts at periumbilical area that progress to right lower quadrant and is usually accompanied by low grade fever, anorexia, nausea, and sometimes by vomiting. Similarly, the abdomen is tense, and the client usually flexes the right hip to relieve the discomfort. Generally, the location of the appendix may also influence the type of pain. For example, if the tip of the appendix is against the rectum, the client may experience pain with defecation. If the tip is near the bladder or against a ureter, the client may experience pain with urination and if the appendix perforates, clients experience more diffuse abdominal pain. The abdomen may also be distended secondary to paralytic ileus $(9,10)$.

Extreme age, delay in presentation, stage or duration of acute appendicitis, intake of antibiotics outside health care institutions, presence of comorbid condition and immunologic status of the patient can affect treatment outcomes of acute appendicitis. Morbidity and mortality rates after surgical treatment of acute appendicitis is still a major challenge in developing world $(3,11)$.

The commonly encountered complications in surgical practices related to acute appendicitis can be preoperative like perforation which can lead to local or generalized peritonitis, appendicial abscess and mass or post-operative complications such as superficial and deep wound infections and wound dehiscence, prolonged ileus, and pneumonia, bowel obstruction and intra-abdominal abscesses( 12,13$)$.

Therefore, assessing the treatment outcome and the factors associated with acute appendicitis is crucial to prevent related complications. 


\section{Methods And Materials \\ Study design, area and period}

Institutional based cross sectional study was employed among patients who have had appendectomy in Debre Markos referral hospital (DMRH). The hospital is located in Debre Markos town in the North West part of Ethiopia $299 \mathrm{Km}$ from the capital, Addis Ababa and $263 \mathrm{Km}$ away from Bahir Dar. It serves as a referral hospital for east Gojjam administration region and the residences around. The study was conducted by reviewing records from September 11/2018 to March 9/2019 in Debre Markos referral hospital.

\section{Sample size determination and sampling procedure}

All patients, who had operative management for acute appendicitis and admitted at Debre Markos referral hospital from September $11 / 2018$ to March 9 /2019, were included in the study. However, patients with acute appendicitis who had incomplete data record over the variable of interest were excluded from the study. The sample size were determined by census sampling method, in which all acute appendicitis cases operated in Debre Markos referral hospital from September 11/2018 to March 9/2019 were included in the study giving a total sample size of 169 patients.

\section{Study variables and operational definitions}

The outcome variable of the study was treatment outcomes of acute appendicitis (favorable and unfavorable) whereas the predictor variables of the study were patient related variables (age, sex, residence), diseases related variables(clinical sign and symptoms, duration of illness, intraoperative findings, preoperative WBC count and index of abdominal ultrasound) and treatment related variables(type of abdominal incision, procedure done, intake of preoperative antibiotics and length of hospital stay).

The following terms were described in such away in this study.

Length of hospital stay-Number of days elapsed while the patient is in the hospital

Outcome -Condition of the patient at discharge (either improved with no postoperative complication/s or developed one or more complications.

Favorable outcome:-Patients who underwent appendectomy for the clinical diagnosis of acute appendicitis, improved and discharged from the hospital without developing postoperative complications following appendectomy.

Unfavorable outcome: Patients with a clinical diagnosis of acute appendicitis who developed one or more postoperative complication(s), e.g. wound infection, intestinal obstruction, or patients with a clinical diagnosis of acute appendicitis who have died in the intra- or postoperative period.

\section{Data collection procedure, quality assurance and analysis}

Data were collected from patient medical records, registration books and anesthesia charts available in the hospital by check lists using two trained data collectors who are both $4^{\text {th }}$ year B.Sc. nursing students. First medical record number (MRN) of patients in the study period was identified from registration books (logbooks). Then their charts were retrieved from card office and those tools including socio demographic characteristics, signs and symptoms, physical findings, out comes, complications encountered, and other relevant items related to the disease were reviewed. Finally data was summarized, analyzed, interpreted and edited. The data were checked for completeness, cleaned coded and entered into Epi-data version 4.2 and then analyzed using statistical product and service solution (SPSS) version 25 statistical software. Bivariate and multivariable logistic regression models were used. Crude odds ratios with 95\% confidence intervals were estimated in the bivariable logistic regression analysis to assess the association between each predictor variable and outcome variable. In the bivariable logistic regression, variables with P-value $<0.2$ were fitted into the multivariable logistic regression analysis. Finally, adjusted odds ratios with their $95 \%$ confidence intervals were estimated to assess the strength of association, and variables with P-value $<0.05$ were considered statistically significant factors. Model fitness was checked using Hosmer-Lemeshow goodness fit test, which was 0.6 . Data quality were assured by training of data collectors, collecting and cross matching of patient charts and surgery registration logbooks before data collection, preparing checklists and supervising and assisting data collectors closely.

\section{Results}

\section{Socio-demographic characteristics}


Out of all 303 patients admitted with a diagnosis of acute abdomen, 169(55.7\%) patients were undergone operative management for a clinical diagnosis of acute appendicitis. Among those having operative management for the clinical diagnosis of acute appendicitis and fulfil the eligibility criteria, 107(63.3\%) were males and $62(36.7 \%)$ were females. Moreover, $69(40.8 \%)$ of patients were urban and $100(59.2 \%)$ were rural dwellers and their mean age was $24.6+11.8$ SD years (Table. 1$)$.

\section{Clinical and investigation profile of patients with Acute Appendicitis}

\section{Clinical Symptoms}

Abdominal pain was invariably the main presenting complaint of patients with acute appendicitis. Among the participants, $119(70.4 \%)$ had an initial periumbilical pain that latter shifted to the Right Lower Quadrant (RLQ) of the abdomen, 33(19.5\%) had right lower quadrant abdominal pain, $14(8.3 \%)$ had generalized abdominal pain, 2(1.2\%) had pelvic pain and 1 (0.6\%) had flank pain. Moreover, $156(92.3 \%), 151(89.3 \%)$ and $149(88.2 \%)$ of the study participants had a presentation of nausea/vomiting, anorexia and fever respectively. Out of the respondents, $7(4.1 \%)$ mentioned constipation, 7(4.1\%) mentioned diarrhea and 11 (6.5\%) mentioned dysuria as their presenting complaints (Table 2).

\section{Clinical Signs}

The physical examination finding of the patients revealed that, $50(29.6 \%)$ patients had temperature $>37.5^{0} \mathrm{C}$ and $153(90.5 \%)$ of them had RLQ abdominal tenderness. The rest, $13(7.7 \%), 3(1.8 \%)$ and $1(0.6 \%)$ of patients had generalized abdominal tenderness, pelvic tenderness and flank tenderness respectively. Only one patient was presented with RLQ abdominal mass. Out of 15(8.8\%) patients who presented peritonitis, 13(7.7\%) were having generalized peritonitis (Table 2).

\section{Investigation findings}

CBC was done for all patients. Of whom, 71(42\%) had raised WBC count ( $>11,000$ cells $/ \mathrm{nl})$. Similarly, abdominal ultrasound was done for $157(92.7 \%)$ patients and the imaging result of these patients indicated that 97 (57.4\%) had acute appendicitis, 35(20.7\%) had perforated appendix, $22(13 \%)$ had appendicial abscess, and $1(0.6 \%)$ had gangrenous appendicitis (Table 2$)$.

\section{Management procedures for Acute Appendicitis}

All patients (100\%) were given preoperative IV antibiotics. The most common type of abdominal incision was RLQ transverse incision (89.3\%; $\mathrm{n}=151)$ followed by midline vertical incision $(6.5 \%$; $=11)$. Moreover, the commonest operative procedure done was appendectomy $(74.6 \%$; $=126)$ followed by appendectomy with abscess drainage (18.9\%; $n=32)$. Majority of patients, $112(66.3 \%)$ stayed in the hospital for $\leq$ three days (Table 3).

The most common intraoperative findings was an inflamed/phlegmonous appendix (39.1\%; $n=66)$ followed by perforated appendix (28.4\%; $n=48)$. The other intra operative findings were appendicular abscess $(24.9 \% ; n=42)$, gangrenous appendix $(5.9 \%$; $n=10)$, fecalith (1.2\%; $n=2)$, appendicular mass $(0.6 \% ; n=1)$, normal appendix $(0.6 \% ; n=1)$ and other findings such as inflammatory peritoneal fluid collection, ectopic kidney, cecal mass and edematous pancreas $(3 \% ; n=5)$. The position of appendix, in almost all of the patients, was retrocecal (99.4\%; $n=168)($ Figure 1$)$.

Among 169 patients who underwent appendectomy for acute appendicitis treatment, 45(26.6\%) of them were developed post-operative complications (unfavorable treatment outcomes). The major post-operative complications (unfavorable treatment outcomes) were wound infection (13.6\%; $n=23)$, pneumonia $(7.02 \% ; n=12)$ intraperitoneal fluid collection $(4.7 \%$; $n=8)$ and death $(1.1 \%$; $n=2) /$ Figure 2 .

\section{Factors affecting treatment outcomes of Acute Appendicitis}

In bivariable logistic regression analysis, elevated WBC count, presence of intraoperative appendicial abscess, peritonitis, temperature and duration of illness before reaching to hospital were statistically associated with treatment outcome of acute appendicitis. However, only two variables were statistically associated with treatment outcome of acute appendicitis after adjusting possible confounders. These were elevated WBC count at the time of presentation and intraoperative appendicial abscess (Table 4). Patients who had elevated WBC count (>11000 cells/nl ) at time of presentation were 4.7 times more likely to develop unfavorable acute appendicitis treatment outcome as compared to those who had no elevated, 4000-1100 cells/nl, WBC count [AOR=4.7; 95\% Cl(1.95, 11.35)]. Similarly, those patients who had an intraoperative appendicial abscess were 3.8 times more likely to have unfavorable acute appendicitis treatment outcome as compared to their counterparts[AOR=3.8; 95\% $\mathrm{Cl}(1.61,9.07)]$. 


\section{Discussion}

In this study, nearly one-fourth (26.6\%) of the patients were developed unfavorable treatment outcomes of acute appendicitis with postoperative complications. The most common unfavorable outcomes were wound infection, pneumonia, intraperitoneal fluid collection and death. This finding is lower than a studies conducted in Kumasi, Ghana (43.1\%)( 14) and Edendale Hospital in Pietermaritzburg, South Africa (44\%)( 15). However this study is comparable with study done at Nottingham, UK that ranges from < $5 \%$ in simple appendicitis to $20 \%$ in cases with perforation and gangrene( 16). The possible explanation for the above discrepancy could be the difference in socioeconomic and organizational setup among countries.

Elevated WBC count at the time of presentation and presence of intraoperative appendiceal abscess were the factors associated with treatment outcome of acute appendicitis in this study. Patients who had elevated WBC count ( $>11000$ cells/nl) at time of presentation were more likely to develop unfavorable acute appendicitis treatment outcome as compared to those who had no elevated WBC count. This was supported by a study done in Kathmandu, Nepal( 17). Similarly, those patients who had an intraoperative appendiceal abscess were more likely to develop unfavorable acute appendicitis treatment outcome as compared to their counterparts. The possible explanation might be due to the fact that the presence of infections can trigger the body's immune system and cause inflammation and tissue damage or delay wound healing.

The most common intraoperative findings was an inflamed/phlegmonous appendix followed by perforated appendix. The other intra operative findings were appendiceal abscess, gangrenous appendix, fecalith, appendicular mass, normal appendix and other findings such as inflammatory peritoneal fluid collection, ectopic kidney, and cecal mass and edematous pancreas. This finding is in line with the study conducted at Iran( 18), Nottingham(UK)( 16) and USA( 19). This might be related to the duration of illness prior to admission to hospital as $95 \%$ of patients with an intraoperative appendiceal abscess came after three days of onset of their illness.

Consistent with studies done in Tikur Anbessa teaching hospital (52\%), (2), Gondar University hospital (34.6\%) (3), Yirgalem hospital (44\% for simple appendicitis and $45.5 \%$ for perforated appendicitis)(20), Goba referral hospital(21), Suhul general hospital(54.2\%)( 22), and Sina hospital, Iran (56.8\%)(23) acute appendicitis is the leading (55.7\%) cause of acute abdomen in this study.

In this study, majority of patients were developed acute appendicitis in the first and second decades of their life. This age group is consistent with studies conducted at Glemso zonal hospital, Eastern Ethiopia( 24$)$ and different parts of united kingdom $(5,6)$. However, majority of cases (42.8\%) occurred at the third decade of life in Lagos, Nigeria(25).

In this study, abdominal pain which started at periumbilical area and then radiating to the right lower quadrant of the abdomen was the commonest symptom followed by vomiting, anorexia and fever whereas tenderness at Mc Burney's point was the commonest sign followed by elevated temperature. This finding was in line with studies conducted at United Kingdom (6, 16), Brazil (26), Thailand( 27) and Portugal (28) . This might be due to the inflammatory process at the appendix.

All patients who were diagnosed as acute appendicitis were given preoperative IV antibiotics. The most common type of abdominal incision was RLQ transverse incision followed by midline vertical incision. Moreover, the commonest operative procedure done was appendectomy followed by appendectomy with abscess drainage.

\section{Limitation of the study}

Since the study depend on medical records, treatment outcomes of acute appendicitis may be underestimated due to exclusion of incomplete records.

\section{Conclusion}

Among patients who underwent appendectomy for the treatment of acute appendicitis, nearly one-fourth of them were developed unfavorable treatment outcomes. The most common unfavorable outcomes were wound infection, pneumonia, intraperitoneal fluid collection and death. Elevated WBC count at the time of presentation and presence of intraoperative appendiceal abscess were the factors associated with unfavorable treatment outcome of acute appendicitis. Majority of patients were developed acute appendicitis in the first and second decades of their life. In all patients abdominal pain was invariably the main presenting complaint and the most common physical finding was RLQ tenderness.

\section{Recommendation}

Health care providers should immediately evaluate patients with abdominal pain for acute appendicitis and further validate it by using proper history, physical examination \& investigations such as CBC and abdominal ultrasound to support the clinical diagnosis is very important.

Early appendectomy after confirmatory diagnosis of acute appendicitis is recommended especially for those having features of peritonitis, raised WBC count and delayed presentation to reduce the risk of developing unfavorable treatment outcomes. 


\section{Declaration}

\section{Competing interests}

The authors declared that they have no any competing of interest

\section{Ethical approval}

The study was conducted after obtaining official permission to undertake this study from, Debre Markos University, College of Health Sciences Research and Ethical Review Committee. Then support and permission letter were provided to Debre Markos referral hospital (DMRH). Staffs at the Card room, surgical ward and operation room were informed about the purpose of the study and verbal consent was obtained. Confidentiality of patient's information were assured and information was recorded anonymously.

\section{Consent for publication}

Not applicable

Acknowledgments

Authors would like to thank Debre Markos University, Debre Markos referral hospital, data collectors, and supervisors.

\section{Funding}

We have not obtained any fund for this study

\section{Availability of data}

All relevant data are within the paper and its Supporting Information files.

\section{Authors' contributions}

$A D$ : conceived, designed the study, supervised the data collection, and performed the data analysis, interpretation of the result, and drafting the manuscript. AM and BK participated in designed the study, data analysis and data interpretation, editing the manuscript. All authors read and approved the final manuscript

\section{References}

1. Mayumi T, Yoshida M, Tazuma S, Furukawa A, Nishii O, Shigematsu K, et al. The practice guidelines for primary care of acute abdomen 2015. Journal of General and Family Medicine. 2016;17(1):5-52.

2. Kotiso B, Abdurahman Z. Pattern of Acute Abdomen in Adult Patients in Tikur Anbessa Teaching Hospital, Addis Ababa, Ethiopia. East and central African journal of surgery. 2007;12(1):47-52.

3. Tsegaye S, Osman M, Bekele A. Surgically Treated Acute Abdomen at Gondar University Hospital, Ethiopia. East and central African journal of surgery. 2007;12(1):53-7.

4. Biondi A, Di Stefano C, Ferrara F, Bellia A, Vacante M, Piazza L. Laparoscopic versus open appendectomy: a retrospective cohort study assessing outcomes and cost-effectiveness. World Journal of Emergency Surgery. 2016;11(1):44.

5. Williams N, O'Connell PR. Bailey \& Love's Short Practice of Surgery 26E: Crc Press; 2013.

6. Froggatt P, Harmston C. Acute appendicitis. Surgery (Oxford). 2011;29(8):372-6.

7. Poon SHT, Lee JWY, NG KM, Chiu GWY, Wong BYK, Foo CC, et al. The current management of acute uncomplicated appendicitis: should there be a change in paradigm? A systematic review of the literatures and analysis of treatment performance. World Journal of Emergency Surgery.

2017;12(1):46.

8. Hobler KE. Acute and suppurative appendicitis: disease duration and its implications for quality improvement. Permanente Med J. 1998;2(2):5-8.

9. Timby BK, Smith NE. Introductory medical-surgical nursing: Lippincott Williams \& Wilkins; 2013.

10. Sellars H, Boorman P. Acute appendicitis. Surgery (Oxford). 2017;35(8):432-8.

11. Nouri S, Kheirkhah D, Soleimani Z. The risk factors for infected and perforated appendicitis. J Res Med Dental Sci. 2017;5(1):23-6. 
12. Bekele A, Mekasha A. Clinical profile and risk factors for perforation of acute appendicitis in children. East African medical journal. 2006;83(8):434-9.

13. Andersson RE. The natural history and traditional management of appendicitis revisited: spontaneous resolution and predominance of prehospital perforations imply that a correct diagnosis is more important than an early diagnosis. World journal of surgery. 2007;31(1):86-92.

14. Ohene-Yeboah M, Togbe B. An audit of appendicitis and appendicectomy in Kumasi, Ghana. West African journal of medicine. 2006;25(2):13843.

15. Kong VY, Bulajic B, Allorto NL, Handley J, Clarke DL. Acute appendicitis in a developing country. World journal of surgery. 2012;36(9):2068-73.

16. Humes D, Simpson J. Acute appendicitis. Bmj. 2006;333(7567):530-4.

17. Subedi N, Dangol U, Adhikary M, Pudasaini S, Baral R. Acute appendicitis: a 2-year review of clinical presentation and histopathology. Journal of pathology of Nepal. 2011;1(2):104-7.

18. Zarandi NP, Parsijani PJ, Bolandparvaz S, Paydar S, Abbasi H. Accuracy of Surgeon's Intraoperation Diagnosis of Acute Appendicitis, Compared with the Histopathology Results. Bulletin of Emergency \& Trauma. 2014;2(1):15.

19. Farach SM, Danielson PD, Walford NE, Harmel Jr RP, Chandler NM. Operative findings are a better predictor of resource utilization in pediatric appendicitis. Journal of pediatric surgery. 2015;50(9):1574-8.

20. Asefa Z. Acute appendicitis in Yirgalem Hospital, southern Ethiopia. Ethiopian medical journal. 2002;40(2):155-62.

21. Tasew B etal. Presentation and Outcome of Acute Abdomen in Goba Referral Hospital, Goba, Southeast Ethiopia: Retrospective Study. SM Journal of Family Medicine. 2017

22. Gebre S. Causes and Outcome of Surgically Treated Non-Traumatic Surgical Acute Abdomen in Suhul General Hospital, Shire, Northwest Tigray, Ethiopia, a Retrospective Study. American Scientific Research Journal for Engineering, Technology, and Sciences (ASRJETS). 2016;16(1):74-89.

23. Laal M, Mardanloo A. Acute abdomen; pre and post-laparotomy diagnosis. International Journal of Collaborative Research on Internal Medicine \& Public Health. 2009;1(5):156.

24. Tegenu H. Management Outcome of Acute Appendicitis and Associated factors among general surgery department attendants in Glemso Zonal Hospital, west Harergae, Eastern Ethiopia: Harmaya University; 2016.

25. Fashina I, Adesanya A, Atoyebi O, Osinowo O, Atimomo C. Acute appendicitis in Lagos: a review of 250 cases. The Nigerian postgraduate medical journal. 2009;16(4):268-73.

26. Petroianu A. Diagnosis of acute appendicitis. International Journal of Surgery. 2012;10(3):115-9.

27. Tantarattanapong S, Arwae N. Risk factors associated with perforated acute appendicitis in geriatric emergency patients. Open access emergency medicine: OAEM. 2018;10:129.

28. Resende F, Almeida AB, Maia JC, Melo RB. Challenges in uncomplicated acute appendicitis. Journal of Acute Disease. 2016;5(2):109-13.

\section{Tables}

Table 1: Socio-demographic characteristics of patients operated for a clinical diagnosis of acute appendicitis at Debre Markos referral hospital from September 11/2018 to March 9/2019 (n=169). 


\begin{tabular}{lll}
\hline Variables & Frequency & Percentage \\
\hline Sex & 107 & 63.3 \\
$\quad$ Male & 62 & 36.7 \\
$\quad$ Female & & \\
Residence & 69 & 40.8 \\
Urban & 100 & 59.2 \\
Rural & & \\
Age group & 66 & 39.1 \\
</=20 years & 64 & 37.9 \\
21-30 years & 25 & 14.5 \\
31-40 years & 9 & 5.3 \\
41-50 years & 5 & 3 \\
>50 years &
\end{tabular}

Table 2: Clinical and investigative findings of patients operated for a clinical diagnosis of acute appendicitis at DMRH from September 11/2018 to March 9/2019 ( $\mathrm{n}=169)$. 


\begin{tabular}{|c|c|c|}
\hline riables & Frequency & Percentage \\
\hline \multicolumn{3}{|l|}{ nical symptoms } \\
\hline \multicolumn{3}{|l|}{ dominal pain } \\
\hline 'eriumbilical pain shifting to the RLQ & 119 & 70.4 \\
\hline iLQ abdominal pain & 33 & 19.5 \\
\hline jeneralized pain & 14 & 8.3 \\
\hline 'elvic pain & 2 & 1.2 \\
\hline 'lank pain & 1 & 0.6 \\
\hline \multicolumn{3}{|l|}{ usea and vomiting } \\
\hline Yes & 156 & 92.3 \\
\hline No & 13 & 7.7 \\
\hline \multicolumn{3}{|l|}{ orexia } \\
\hline 'es & 151 & 89.3 \\
\hline No & 18 & 10.7 \\
\hline \multicolumn{3}{|l|}{ ver } \\
\hline 'es & 149 & 88.2 \\
\hline Jo & 20 & 11.8 \\
\hline \multicolumn{3}{|l|}{ nstipation } \\
\hline res & 7 & 4.1 \\
\hline No & 162 & 95.9 \\
\hline \multicolumn{3}{|l|}{ irrhea } \\
\hline 'es & 7 & 4.1 \\
\hline No & 162 & 95.9 \\
\hline \multicolumn{3}{|l|}{ suria } \\
\hline 'es & 11 & 6.5 \\
\hline Jo & 158 & 93.5 \\
\hline \multicolumn{3}{|l|}{ ration of illness before reaching DMRH } \\
\hline$</=3$ days & 90 & 53.3 \\
\hline$>3$ days & 79 & 46.7 \\
\hline \multicolumn{3}{|l|}{ nical signs } \\
\hline \multicolumn{3}{|l|}{ mperature } \\
\hline$</=37.5^{0} \mathrm{C}$ & 119 & 70.4 \\
\hline$>37.5^{0} \mathrm{C}$ & 50 & 29.6 \\
\hline \multicolumn{3}{|l|}{ dominal tenderness } \\
\hline RLQ tenderness & 153 & $\begin{array}{l}90.5 \\
7.7\end{array}$ \\
\hline Generalized tenderness & $\begin{array}{l}13 \\
2\end{array}$ & 1.7 \\
\hline Pelvic tenderness & 2 & 1.2 \\
\hline Flank tenderness & 1 & 0.6 \\
\hline \multicolumn{3}{|l|}{ Q mass } \\
\hline 'es & 168 & 99.4 \\
\hline \multirow{2}{*}{\multicolumn{3}{|c|}{ ritonitis }} \\
\hline & 13 & 7.7 \\
\hline $\begin{array}{l}\text { jeneralized } \\
\text {.ocalized }\end{array}$ & 2 & 1.2 \\
\hline \multicolumn{3}{|l|}{ vestigations } \\
\hline \multicolumn{3}{|l|}{$3 \mathrm{C}$ count } \\
\hline :000-1100 cells/nl & 98 & 58 \\
\hline >11000 cells/nl & 71 & 42 \\
\hline \multicolumn{3}{|l|}{ dominal ultrasound } \\
\hline Jone & 157 & 92.9 \\
\hline ot done & 12 & 7.1 \\
\hline \multicolumn{3}{|l|}{ lex of abdominal ultrasound } \\
\hline 'erforated & 35 & 20.7 \\
\hline ppendicular abscess & 22 & 13 \\
\hline cute appendicitis & 97 & 57.4 \\
\hline
\end{tabular}




\begin{tabular}{lll} 
angrenous & 1 & 0.6 \\
thers & 2 & 1.2 \\
\hline
\end{tabular}

Table 3:Manegment related profiles of patients operated for a clinical diagnosis of acute appendicitis at DMRH from September $11 / 2018$ to March 9/2019 ( $\mathrm{n}=169)$.

\begin{tabular}{lll}
\hline Variables & Frequency & Percentage \\
\hline Type of incision & 151 & 89.3 \\
RLQ transverse incision & 2 & 1.2 \\
Gridiron incision & 11 & 6.5 \\
Midline vertical incision & 5 & 3.0 \\
Both gridiron and midline vertical incision & 5 & \\
Type of operative procedure & & 74.6 \\
Appendectomy only & 126 & 18.9 \\
Appendectomy and abscess drainage & 32 & 0.6 \\
Drainage only & 1 & 5.3 \\
Appendectomy and drainage & 9 & 0.6 \\
Other procedure & 1 & \\
Duration of hospital stay & & 66.3 \\
Less than or equal to 3 days & 112 & 29.0 \\
4-7 days & 49 & 4.7 \\
>7 days & 8 & \\
Status of patient at discharge & & 98.8 \\
Improved & 167 & 1.2 \\
Dead & 2 &
\end{tabular}

Table 4: Factors affecting treatment outcome of acute appendicitis at Debre Markos referral hospital from September $11 / 2018$ to March 9/2019 (n=169) 


\begin{tabular}{|c|c|c|c|c|c|}
\hline \multirow[t]{2}{*}{ riables } & \multicolumn{2}{|c|}{$\begin{array}{l}\text { Acute Appendicitis } \\
\text { treatment outcome }\end{array}$} & \multirow[t]{2}{*}{$\begin{array}{l}\text { COR } \\
{[95 \% \mathrm{CI}]}\end{array}$} & \multirow[t]{2}{*}{$\begin{array}{l}\text { AOR } \\
{[95 \% \mathrm{CI}]}\end{array}$} & \multirow[t]{2}{*}{$\begin{array}{l}\mathrm{P}- \\
\text { value }\end{array}$} \\
\hline & & le Favorable & & & \\
\hline \multicolumn{6}{|l|}{ C count } \\
\hline 1000 cells $/ \mathrm{nl}$ & $35(20.7 \%)$ & $36(21.3 \%)$ & $8.5(3.83,19.09)$ & $4.7(1.95,11.35)$ & 0.001 \\
\hline 00-11000cells/nl & $10(5.9 \%)$ & $88(52 \%)$ & 1 & 1 & \\
\hline \multicolumn{6}{|l|}{ Jendicial abscess } \\
\hline es & $25(14.7 \%)$ & $17(10 \%)$ & $7.8(3.6,17.15)$ & $3.8(1.61,9.07)$ & 0.002 \\
\hline No & $20(11.8 \%)$ & $107(63.3 \%)$ & 1 & 1 & \\
\hline \multicolumn{6}{|l|}{ itonitis } \\
\hline es & $10(5.9 \%)$ & $5(3 \%)$ & $6.8(2.18,21.21) 1$ & $2.8(0.82,9.55)$ & 0.098 \\
\hline o & $35(20.7 \%)$ & $119(70.4 \%)$ & & 1 & \\
\hline \multicolumn{6}{|l|}{ nperature } \\
\hline \multirow[t]{2}{*}{7.5} & $16(9.4 \%)$ & $103(60.9 \%)$ & $18.8(4.1,19.1)$ & 1 & \\
\hline & $29(17.1 \%)$ & $21(12.4 \%)$ & & $1.7(0.58,5.50)$ & 0.310 \\
\hline \multicolumn{6}{|l|}{7.5} \\
\hline \multicolumn{6}{|c|}{ ation of illness before hospital } \\
\hline \multicolumn{6}{|c|}{ I=3days } \\
\hline \multirow[t]{2}{*}{3 days } & $12(7.1 \%)$ & $78(46.1 \%)$ & 1 & 1 & \\
\hline & $33(19.5 \%)$ & $46(27.2 \%)$ & $4.6(2.19,9.91)$ & $0.9(0.31,2.86)$ & 0.928 \\
\hline
\end{tabular}

\section{Figures}

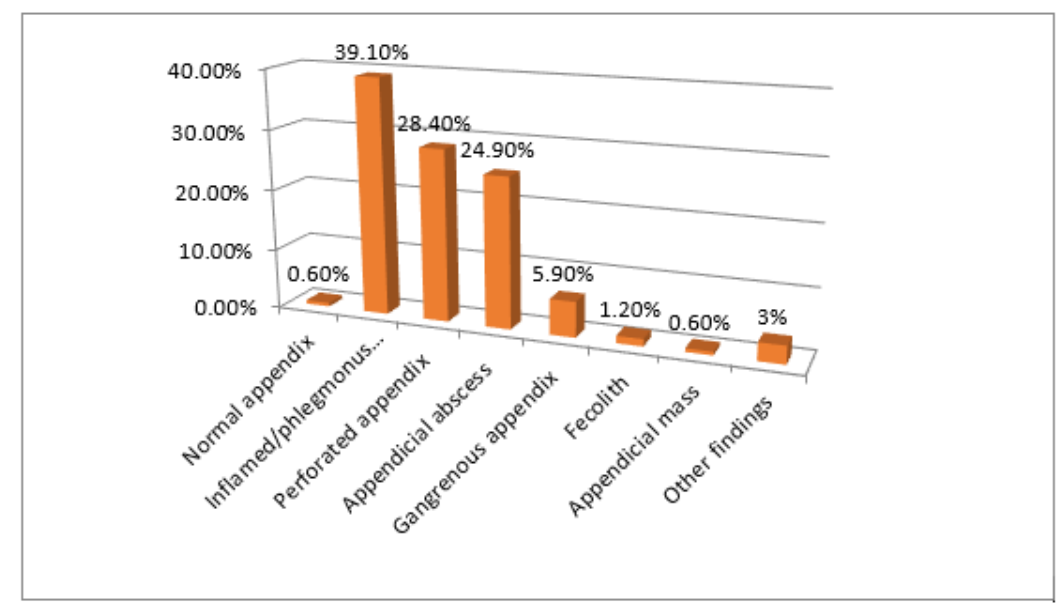

Figure 1

Intraoperative findings of patients operated for a clinical diagnosis of acute appendicitis at Debre Markos referral hospital from September $11 / 2018$ to March 9/2019 ( $n=169)$. 


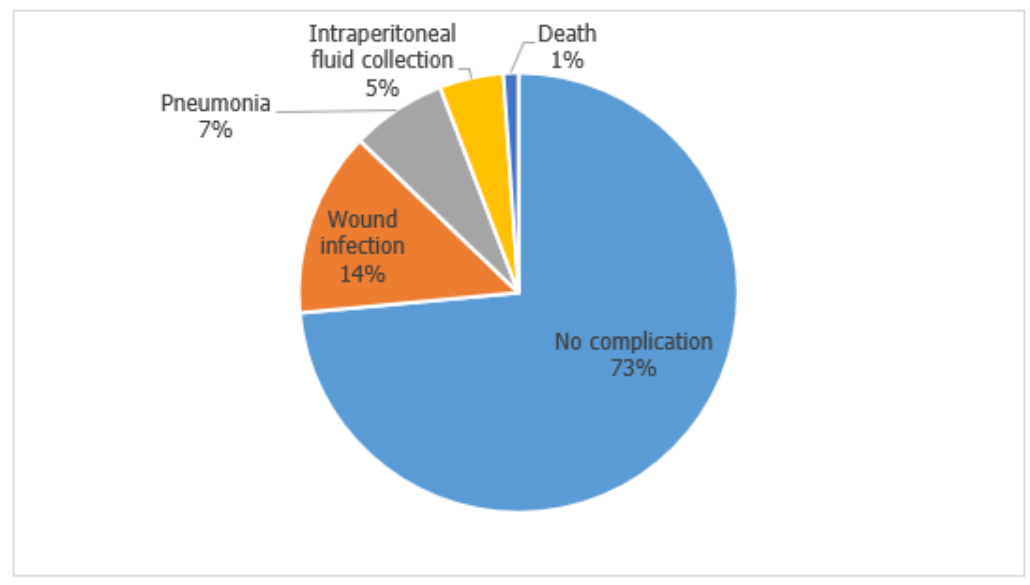

Figure 2

Post operation complications of patients operated for a clinical diagnosis of acute appendicitis at DMRH from September 11/2018 to March 9/2019. 